\title{
Enfrentando desafios: um relato de experiência no ensino superior amapaense sobre o uso de tecnologias educacionais em tempos de pandemia
}

Overcoming challenges: an experience report in amapaense higher education on using educational technologies in the pandemic era

Enfrentando desafíos: un informe de experiencia en la educación superior amapaense sobre el uso de tecnologías educativas en tiempos de pandemia

Emerson dos Santos Rocha ORCID: https://orcid.org/0000-0001-9063-0046 Instituto Macapaense de Melhor Ensino Superior, Brasil

E-mail: emerson.srocha@outlook.com

Ana Cristina Almeida Alves

ORCID: https://orcid.org/0000-0002-0919-0168 Instituto Macapaense de Melhor Ensino Superior, Brasil

E-mail: almeidaalvescristinaana@gmail.com

Iasmin dos Santos Oliveira

ORCID: https://orcid.org/0000-0003-4876-4803 Instituto Macapaense de Melhor Ensino Superior, Brasil

E-mail: Iasmin.olvr@outlook.com

Jamily Emanoely Costa dos Santos

ORCID: https://orcid.org/0000-0002-0169-9066 Instituto Macapaense de Melhor Ensino Superior, Brasil

E-mail: Jamily.snts05@gmail.com

Luiz Fernando Maués da Costa

ORCID: https://orcid.org/0000-0002-4780-6058 Instituto Macapaense de Melhor Ensino Superior, Brasil E-mail: luizluizcosta1@gmail.com

Marillia dos Santos Rocha

ORCID: https://orcid.org/0000-0003-2716-311X Instituto Macapaense de Melhor Ensino Superior, Brasil

E-mail: marillia167@gmail.com

Anderson Luiz Pena da Costa

ORCID: https://orcid.org/0000-0002-7876-0187 Instituto Macapaense de Melhor Ensino Superior, Brasil E-mail: pena.biologo@gmail.com

Antonio Carlos Freitas Souza

ORCID: https://orcid.org/0000-0002-6921-9030

Instituto Macapaense de Melhor Ensino Superior, Brasil Instituto de Pesquisas Científicas e Tecnológicas do Estado do Amapá, Brasil

E-mail: acssilva.junior@gmail.com

Franklin Teixeira Regis

ORCID: https://orcid.org/0000-0002-0789-6204 Instituto Macapaense de Melhor Ensino Superior, Brasil

E-mail: fktregis@gmail.com

Nádia Rosana Matos Soares

ORCID: https://orcid.org/0000-0003-4699-4752 Instituto Macapaense de Melhor Ensino Superior, Brasil

Universidade Federal do Amapá, Brasil

E-mail: nadiafarm9932@gmail.com

Danay Rosa Dupeyrón Martell

ORCID: https://orcid.org/0000-0003-0220-5213

Instituto Macapaense de Melhor Ensino Superior, Brasil

E-mail: danaydm@gmail.com

\section{Resumo}

No meado de março de 2020, o surto do vírus SARS-CoV-2, causador da pandemia do COVID-19 colocou o mundo em situação emergencial. Diante do alto grau de contagio, e sob a recomendação da OMS, a maioria dos governos, fechou "temporariamente" as instituições educacionais como medida de controle para evitar a disseminação da Covid19. Neste contexto, a forma encontrada para dar continuidade ao semestre letivo no Instituto Macapaense de Melhor 
Ensino Superior (IMMES) foi a mudança súbita do modelo de ensino tradicionalmente presencial para remoto. Para isto, foi implementada a plataforma digital de ensino online Google (MEET e Classroom). Começou deste modo um período desafiador tanto para acadêmicos e professores como para a gestão do curso. Perante o cenário exposto, o presente trabalho consiste em um relato de experiência sobre o uso destas tecnologias no ensino superior amapaense. Os principais desafios levantados foram a precariedade no sistema de Internet no estado, situação que foi agravada pelo apagão sofrido no estado em novembro de 2020; a falta de capacitação profissional na modalidade remota (evidenciando o Gap tecnológico de uma geração de professores) e o estabelecimento de um equilíbrio entre as rotinas profissionais e pessoais. O estudo também revelou aspectos positivos do ensino online, demonstrando que o Google classroom é uma ferramenta profícua para o ensino superior face aos fatores que ainda impossibilitam a volta às aulas presenciais. A pandemia do coronavírus forçou uma súbita adaptação à aprendizagem online e o impacto disso pode mudar permanentemente a visão tradicional sobre a Educação Superior.

Palavras-chave: Tecnologias educacionais; Google sala de aula; Ensino remoto; COVID-19; IMMES.

\begin{abstract}
In mid-March 2020, the outbreak of the SARS-CoV-2, the virus behind the COVID-19 pandemic, placed the world in an emergency. In view of the high degree of transmission, and according to the WHO recommendations, most governments closed "temporarily" all the educational institutions as a control measure to prevent the dissemination of Covid-19. In this context, the only way found to continue the academic course in the Instituto Macapaense de Melhor Ensino Superior (IMMES) was the sudden change from traditional in-person teaching to remote teaching. For this purpose, Google MEET and Classroom were implemented as the digital online learning platform. Thus, a challenging period began for both academics and teachers. Given this scenario, the present work consists of an experience report on the use of these technologies in higher education in the Amapá state. The main challenges raised in this report were the precariousness of the state's Internet system, a situation that was aggravated by the blackout suffered in the state in November 2020; the lack of professional training in the remote modality (showing the technological gap of a generation of teachers) and the creation of a balance between professional and personal routines. On the other hand, the study also revealed positive aspects of online education, showing that the Google classroom is a useful tool for higher education in view of the factors that still make the return to in-person classes impossible. The coronavirus pandemic forced a sudden adaptation to online learning and the impact of this could permanently change the traditional view on Higher Education.
\end{abstract}

Keywords: Educational technologies; Google classroom; Remote learning; COVID-19; IMMES.

\title{
Resumen
}

A mediados de marzo de 2020, el brote del virus SARS-CoV-2, que provocó la pandemia de COVID-19, puso al mundo en una situación de emergencia. En vista del alto grado de contagio, y por recomendación de la OMS, la mayoría de los gobiernos cerraron "temporalmente" las instituciones educativas como medida de control para prevenir la diseminación del Covid-19. En este contexto, la alternativa encontrada para dar continuidad al semestre en el Instituto Macapaense de Melhor Ensino Superior (IMMES), fue el cambio brusco del modelo tradicionalmente presencial a la educación a distancia. Para ello, se implementó la plataforma de educación digital en línea Google (MEET y Classroom). Así comenzó un período desafiante tanto para académicos y profesores como para la gestión del curso. Dado el escenario anterior, el presente trabajo consiste en un informe de experiencia sobre el uso de estas tecnologías en la educación superior en Amapá. Los principales desafíos planteados fueron la precariedad del sistema de internet del estado, situación que se vio agravada por el apagón sufrido en el estado en noviembre de 2020; la falta de formación profesional en la modalidad remota (mostrando la brecha tecnológica de una generación de docentes) y el establecimiento de un equilibrio entre las rutinas profesionales y personales. El estudio también reveló aspectos positivos del aprendizaje en línea, demostrando que el Google sala de clase es una herramienta útil para la educación superior en vista de los factores que aún imposibilitan el regreso a las clases presenciales. La pandemia de coronavirus obligó a una adaptación repentina al aprendizaje en línea y el impacto de esto podría cambiar permanentemente la visión tradicional sobre la Educación Superior.

Palabras clave: Tecnologias educativas; Google sala de clase; Aprendizaje remoto; COVID-19; IMMES.

\section{Introdução}

No início de 2020 o mundo foi surpreendido por um novo vírus: a COVID-19, uma infecção respiratória causada pelo coronavírus SARS-CoV-2. O surto começou na China em meados de novembro de 2019 e rapidamente se espalhou para praticamente o mundo todo causando desordem social, colapso na saúde e economias mundiais. O mundo não estava preparado para uma pandemia, as pessoas ficaram aterrorizadas com a forma que o vírus rapidamente se espalhava. No Brasil especificamente, tivemos muitos desafios; desde a reeducação em relação às medidas de prevenção, superlotação na saúde pública, corrupção e desvio de verbas direcionadas à pandemia, conscientização da importância do uso de máscara e também 
os desafios na educação, tanto no ensino básico como no ensino superior (Alencar et al., 2020).

A saída encontrada para recuperar, minimamente, os prejuízos ocasionados pela pandemia e consequente necessidade do distanciamento social, foi o "ensino remoto", as "aulas online" ou o "ensino à distância" - alternativas ao ensino presencial. Neste contexto, os professores viram-se diante da obrigação de redefinir, reinventar e modernizar suas metodologias. Ao mesmo tempo, a familiarização com as Tecnologias da informação e comunicação (TICs) passou a ser fundamental para o setor educacional. Em nenhum momento da nossa história, os caminhos da criatividade estiveram tão abertos para os educadores (Alencar et al., 2020). Para os acadêmicos, a pandemia trouxe novas tecnologias de ensino e tiveram que "aprender a estudar", sem a presença física de um professor, aumentando a proatividade na busca pelo conhecimento.

Há 12 anos Organização Mundial da Saúde (OMS) declarava a pandemia de gripe A H1N1 e o mundo teve que lidar com esse novo vírus que na época ainda era conhecido como gripe suína. A mini-série documental denominada Pandemic (2020) mostra o trabalho de pesquisadores na busca de uma vacina capaz de combater diversas variações do vírus influenza, vírus que transmite a gripe A H1N1. Logo no primeiro capítulo da série podemos ver o cientista americano Dennis Carroll (1960) falando sobre como possíveis pandemias podem surgir através do vírus influenza. Criador do Programa de Ameaças de Doenças Infecciosas, dedicados a descobrir as zoonoses com potencial para se tornar pandemia letais - como a do coronavírus, ele trabalha na busca da detecção precoce de vírus. A mini-série foi ao ar em janeiro de 2020 na plataforma de streaming Netflix, Pandemic nos leva a refletir sobre o quão grave pode ser uma nova pandemia global. Carroll (1960) comenta sobre a pandemia mais letal do mundo ocorrida em 1918 que matou cerca de 50 a 100 milhões de pessoas, e cita também que, mais cedo ou mais tarde haverá uma nova pandemia como esta, e que por isso, trabalha em pesquisas para descobrir vacinas para inibir potenciais pandemias de gripe no mundo através do vírus influenza. O cientista enfatiza que os cuidados e higiene pessoais podem ser cruciais para o controle de transmissão dos vírus.

"Lembre-se: os vírus não se espalham, nós é que espalhamos o vírus. E por sermos nós que espalhamos o vírus, temos a oportunidade de frear sua transmissão ao adotar esses cuidados. "[Alencar et al., 2020]

- Carroll, Dennis 1960.

A doença conhecida como COVID-19 é um quadro infeccioso causado pelo vírus SARS-CoV-2, um beta- coronavírus pertencente à família coronaviridae (Gravinatti et al., 2020). Esta enfermidade possuí como principais sintomas tosse seca acompanhada de febre e sensação de cansaço em quadros leves e moderados, podendo também apresentar perda de paladar e olfato, erupções cutâneas, dores de garganta, e diarreia, no entanto, estes sintomas são pouco comuns. Além disso, em quadros graves, a infecção pode desencadear intensas respostas imunológicas ao nível sistêmico e local no trato respiratório, implicando evolução para desconforto respiratório seguido de síndrome respiratória aguda, e óbito caso o indivíduo afetado não receba cuidados intensivos (Wu \& McGoogan, 2020).

Ressaltando que o SARS-CoV-2 é um agente infeccioso com elevada transmissibilidade, na qual diferentes estudos apontam que este vírus possui um número reprodutivo superior a 1 , ou seja, possui um elevado risco epidêmico (Dharmaratne et al., 2020; Liu et al., 2020; Zhang et al., 2020). Porém, quando as características da doença, seu agente etiológico, poder de transmissibilidade e sua elevada capacidade de colapsar os serviços de saúde foram reconhecidos, já era tarde demais. De meados do fim do ano de 2019 até o início de 2020 a COVID-19 se tornou uma doença pandêmica de natureza emergente, ou seja, foi a primeira vez que a humanidade enfrenta esta doença, vindo a pandemia a ser declarada pela Organização Mundial da Saúde em 11 de março de 2020 (Cucinotta \& Vanelli, 2020).

Neste contexto, esta doença viral afetou milhares de pessoas e resultou em incontáveis mortes, concomitantemente com profundos impactos culturais, econômicos, políticos, sociais, psicológicos, e acima de tudo sobre a forma como a humanidade vem se reinventado no quesito comunicação por meio de diferentes aplicativos e plataformas digitais; 
revolucionando todo um sistema laboral em diferentes setores, incluindo o setor da educação (Buheji et al., 2020; Fernandes, 2020; Maital \& Barzani, 2020).

Nesse sentindo, considerando o paradigma do estruturalismo funcional oriundo da abordagem sociológica francesa, a partir das ideais de Émile Durkheim, as instituições de ensino possuem funções manifesta e latente, onde a interação alunoprofessor direcionada ao cumprimento de um currículo educacional básico e posterior habilitação profissional representa a função manifesta, enquanto que os aspectos intrínsecos da socialização entre os atores sociais envolvidos no contexto educacional representam as funções latentes (Parhanudin \& Mataram, 2020), que são de suma importância para a inserção dos indivíduos nas estruturas sociais onde representarão papéis específicos como profissionais dentro da sociedade (Awwalu, 2020; Lan et al., 2017; Rose et al., 2017; Barreto, Amorim \& Cunha, 2020).

Neste âmbito, as instituições acadêmicas de todo o país estão em caráter emergencial, adotando o ensino em modalidade remota, estando sujeitas a se reinventarem e ressignificarem suas práticas através de novas experiências e vivências. Ressaltando que a vivência é um elemento que confere intensidade e importância a um evento ou ocorrido, podendo ser construída com bases racionais ou não, enfatizando que a experiência, ou seja, o "sentir na pele" é um fator a priori da vivência, que pode se diferenciar ao nível de coletivo, devido à infinidade de fatores que podem influenciar na percepção sensorial, na atribuição de significados à vivência, assim como sua utilidade no cotidiano (Viesenteiner, 2013).

E para a pesquisa qualitativa, os estudos com foco na vivência se preocupam com a percepção dos objetos de estudo sobre um determinado fenômeno, se utilizando de questionários ou entrevistas, com o intuito de extrair conteúdos que possam ser classificados como genéricos ou peculiares entre os participantes da pesquisa, seguido de classificações teóricas que auxiliem na compreensão do fenômeno através das perspectivas analisadas (Matão et al., 2011; Ranieri \& Barreira, 2012).

Vivemos hoje um grande desafio, por força da realidade, que mesmo que iniciado em caráter provisório pode se tornar parcialmente permanente como parte de um novo modelo de ensino híbrido. Se fazendo importante refletir sobre como a pandemia possa ter afetado as funções manifestas e latentes do ensino superior, o presente trabalho considera que no ambiente de ensino, alunos e docentes vivenciaram a pandemia de maneira individual, mas ao mesmo tempo experienciaram as mudanças de forma coletiva. Perante este cenário, o interesse deste estudo é expor algumas vivências de indivíduos da comunidade acadêmica (discentes e docentes) da faculdade de farmácia do IMMES e fazer uma reflexão em equipe sobre os principais aspectos positivos e negativos vivenciados durante este processo de readaptação nas práticas educativas.

\section{Metodologia}

\subsection{Descrição da área de estudo e equipe entrevistada}

O presente trabalho surgiu com o intuito de promover uma reflexão a respeito da experiência vivenciada, ou seja, desafios e pontos positivos da utilização de tecnologias educacionais, na continuidade do ensino superior no IMMES desde o início da pandemia, período em que foram suspensas as atividades presencias e que se estende até os dias atuais. Assim sendo, um ano e dois meses após a implementação da plataforma Google Suite e Classroom como ferramentas de ensino remoto, foram escritos vários depoimentos individuais baseados em seis perguntas norteadoras resumidas na Tabela 1. Cabe mencionar que os questionários foram aplicados de forma individual via WhatsApp.

Cabe mencionar que o IMMES é uma instituição de ensino superior genuinamente amapaense, que iniciou sua trajetória como instituição de ensino superior em março de 2002, tendo como maior objetivo ofertar educação superior de qualidade. Todos seus cursos foram idealizados para serem $100 \%$ presenciais. Dentre os cursos que funcionam atualmente está o curso de Farmácia, objeto deste estudo, cuja matriz curricular consta de várias disciplinas que compreendem carga horária teórica e também experimental. 
Tabela 1. Relação de Perguntas Norteadoras do Estudo.

\section{Perguntas Norteadoras do Estudo}
1. Sobre qual experiência você quer contar?
2. O que você gostaria de contar sobre a experiência?
3. O que você e a sua equipe aprenderam com essa experiência?
4. Que desafios foram encontrados para o seu desenvolvimento?
5. O que você mais gostou e o que você não gostou?
6. Pensando no que você descreveu sobre a sua experiência, o que mais ainda poderia ser feito?

Nota: As perguntas foram extraídas do Instrutivo para elaboração de relato de experiência de estágio em nutrição em saúde coletiva da universidade federal de juiz de fora.

Fonte da tabela: Autoria própria.

Por ser um relato de experiência, o artigo em tela tomou como base a vivência de 11 indivíduos, sendo cinco professores (45.5\%) e seis acadêmicos de diferentes semestres do curso de Farmácia do IMMES (27,25 \% calouros e 27,25 veteranos, totalizando $54.5 \%$ de acadêmicos) (Figura 1), todos integrantes da Liga Acadêmica de Química do IMMES (LAQUIMMES). As características gerais dos indivíduos da equipe entrevistada estão relacionadas na Tabela 2.

É importante destacar que dentre as pessoas entrevistadas, algumas já ministravam aulas ou cursavam o curso de Farmácia do IMMES enquanto outros iniciaram as atividades nesta instituição de ensino superior já na modalidade remota no período da pandemia, o que pode gerar opiniões diversas mesmo que a equipe pode ser considerada pequena.

Tabela 2. Características da equipe entrevistada.

\begin{tabular}{|c|c|c|c|}
\hline Indivíduo & Sexo & Idade & Formação Acadêmica \\
\hline$P 1$ & $\boldsymbol{F}$ & 42 & Química \\
\hline$P 2$ & $\boldsymbol{F}$ & 50 & Química e Farmacêutica \\
\hline P3 & $M$ & 33 & Biólogo \\
\hline$P 4$ & $M$ & 29 & Biólogo e Farmacêutico \\
\hline P5 & $M$ & 31 & Farmacêutico \\
\hline$V 1$ & $\boldsymbol{F}$ & 22 & Graduando de Farmácia \\
\hline$V 2$ & $\boldsymbol{F}$ & 20 & Graduando de Farmácia \\
\hline$V 3$ & $M$ & 36 & Graduado em Radiologia Médica e Graduando de Farmácia \\
\hline$C 1$ & $\boldsymbol{F}$ & 17 & Acadêmico de Farmácia \\
\hline$C 2$ & $\boldsymbol{F}$ & 18 & Acadêmico de Farmácia \\
\hline C3 & $M$ & 18 & Acadêmico de Farmácia \\
\hline
\end{tabular}

Nota: P: Professor; V: Acadêmico veterano, C: calouro.

Fonte da tabela: Autoria própria. 


\subsection{Processamento dos dados levantados}

Para analisar as questões abertas e tentando identificar as tendências na perspectiva dos professores e alunos em relação às aulas online, foi realizada uma análise de conteúdo convencional. A análise de conteúdo é definida como um nome genérico para uma variedade de análises textuais que normalmente envolvem comparação, contraste e categorização de um conjunto de dados (Schwandt, 1997). Primeiramente foi feita a leitura de cada relato e posteriormente, o levantamento e organização de dados e a classificação de cada elemento (professores, veteranos e calouros), levando em consideração o objetivo do presente estudo. Assim sendo, na seguinte seção, a análise dos resultados, que compõe a parte qualitativa da pesquisa estará organizada em tabelas de acordo com a classificação: Professores, Acadêmicos veteranos e Calouros.

Figura 1. Percentual de entrevistados.

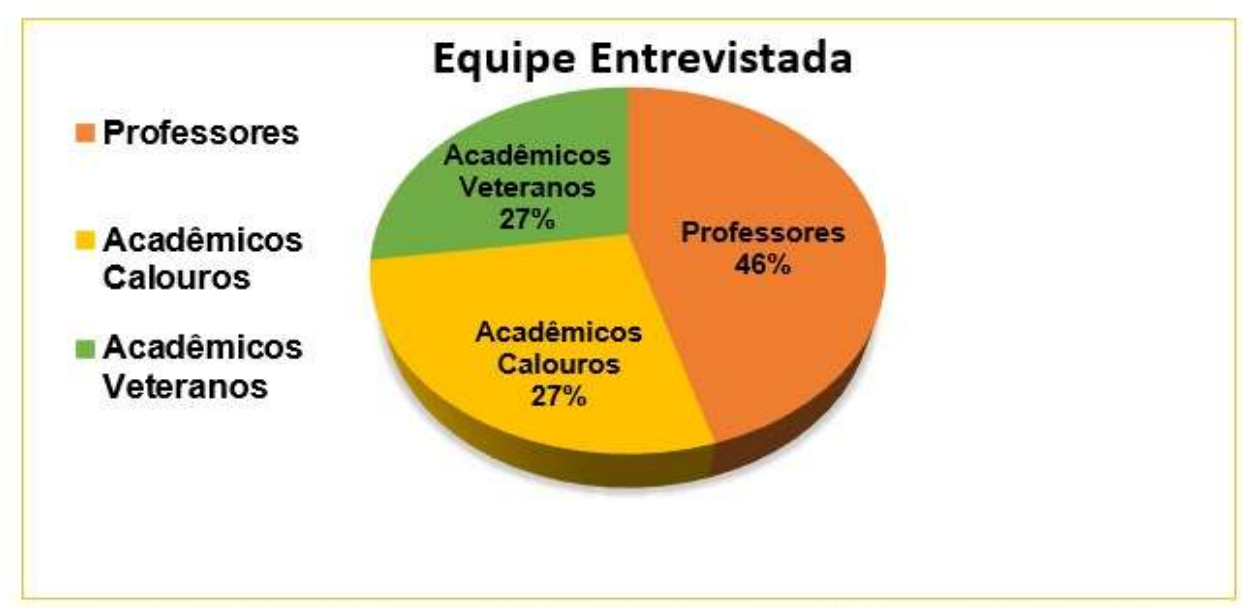

Fonte do gráfico: Autoria própria.

\section{Resultados e Discussão}

\subsection{Perfil geral do respondente}

Como mencionado na seção de metodologia da presente pesquisa, a amostra de respondentes foi definida principalmente em função de sua participação da LAQUIMMES. O perfil dos grupos entrevistados foi brevemente apresentado na Tabela 2 e na Figura 01. As faixas etárias e idades médias dos três grupos foram: professores (29-50; 37 anos), veteranos (20-36; 26 anos) e calouros (17-18; 17,3 anos). Cabe mencionar que dentre os acadêmicos entrevistados, 50\% são alunostrabalhadores os quais, de acordo com Araujo (2019), os alunos que trabalham tem uma preocupação dupla (trabalho e estudos). Neste sentido, o modelo remoto se tornou, em certa medida, conveniente para este tipo de alunos sendo que facilitou a conciliação de horários estudo/trabalho.

Cabe destacar que os efeitos da pandemia impactaram negativamente no aspecto econômico de muitas famílias brasileiras. Diante disto, muitos acadêmicos que antes se dedicavam exclusivamente aos estudos se viram obrigados a trabalhar por conta da situação financeira familiar. Isso se torna mais um desafio na vida acadêmica no ensino remoto, pois, muitos acadêmicos já chegam sobrecarregados e o desempenho cai significativamente. A pandemia não trouxe somente sobrecarga física, mas também a sobrecarga mental e emocional; mais de 600 mil alunos desistiram ou trancaram matrícula no ensino superior no Brasil em 2020 na rede privada. Os dados são de pesquisa da Semesp (Associação Profissional das Entidades Mantenedoras de Estabelecimentos de Ensino Superior no Estado de São Paulo) divulgada em 19 de outubro de 2020 e publicada no UOL, esses dados mostram as dificuldades e uma certa insatisfação com relação ao ensino remoto. O impacto econômico é um dos principais fatores que implicam na evasão temporária ou definitiva, apesar de no ano de 2020 o governo 
ter implantado o auxílio emergencial, o valor de $\mathrm{R} \$ 600,00$ reais era muito pouco para manter as famílias e ainda auxiliar nos estudos.

\subsection{Analise do conteúdo dos relatos}

A análise dos resultados, que compõe a parte qualitativa da pesquisa foi organizada em tabelas, utilizando o método de análise do conteúdo. Primeiramente foi feita a leitura de cada relato, posteriormente, o levantamento e organização de dados e a classificação de cada elemento em três grupos: professores, veteranos e calouros, levando em consideração o objetivo do artigo científico. As percepções dos diferentes grupos entrevistados serão abordadas em conformidade com a ordem apresentada na tabela 2 .

As respostas obtidas do primeiro grupo (resumidas na Tabela 3) foram correlativas com todos pertencentes à categoria de professor. As explanações foram relacionadas com os desafios enfrentados perante a súbita transição do ensino presencial para o ensino remoto, implicando ainda, a Gap de uma geração de professores acostumados à forma tradicional de ensino, levando em consideração a internet deficiente no estado do Amapá.

Como aprendizagem, esse grupo trouxe consigo algumas observações de perspectivas adotadas e elaboradas frente ao contexto pandêmico, declarando que o senso de pertencer e a abertura para novas experiências são atributos importantes que caracterizam e demonstram a conduta de um educador, além da necessidade da aquisição das inúmeras ferramentas digitais disponíveis para o ensino remoto, híbrido e até mesmo presencial. Tendo em vista tornar as aulas mais interativas, sem abrir mão do modelo cartesiano.

Em meio à execução dos processos educacionais, foram levantados alguns impasses presentes nessa modalidade de ensino, como a difícil tarefa de conseguir despertar o interesse dos acadêmicos sem o privilégio da presença física. Outro aspecto interessante está ligado à importância da estratégia de organização e manejo de tempo, pois a impessoalidade do mundo virtual acaba distorcendo a percepção de tempo de trabalho e tempo para outras atividades. Assim, ser disciplinado e constante se torna essencial para satisfazer as demandas do trabalho e as de outras esferas sociais.

Uma matéria publicada pele BBC (2020), conta relatos do professor universitário peruano Juan Francisco Baldeón, referente à desvalorização do estudo remoto, a ausência da resposta não verbal por parte dos alunos e até mesmo uma desconexão com os mesmos:

Ele acredita que a maior dificuldade nas aulas online é o "rompimento do vínculo entre professor e alunos", vital para o processo de aprendizado.

"Parece que os alunos estão de certa forma indiferentes por causa da pandemia", opina Baldeón. "Já tinha dito que estava faltando com respeito à aula e a eles mesmos. E que tinham que participar de qualquer aula, fosse remota ou presencial."

Tendo em vista que as respostas de todos os professores foram condizentes com as discussões apresentadas, foi contestado que a instituição IMMES está tomando todas as providências necessárias para o cumprimento e aperfeiçoamento dos métodos de ensino, destacando ainda que a qualificação continuada do professor é de suma importância para o estímulo do aluno, esse, portanto, deve também manter uma postura colaborativa e responder da melhor forma possível aos encargos a eles direcionados.

Outro ponto exaltado pelos docentes é a relevância das pesquisas qualitativas e quantitativas para avaliar os impactos em um determinado período, podendo contribuir para o futuro da educação, e a reelaboração de aspectos objetivos e subjetivos que dificultem a interação entre alunos e professores. Duarte (2017) traz um olhar elaborado sobre a pesquisa cientifica: 
(...) o conhecimento, concebido como algo incomensurável, torna-se um pressuposto norteador das experiências cotidianas do ser humano. Desta forma, tal afirmativa parece se ajustar de forma contundente quando refere-se à pesquisa de um modo geral - fonte produtora deste conhecimento. Desenvolvida por investigadores, visando a novas descobertas e contribuindo, assim, para a qualidade da vida intelectual.

Tabela 3. Respostas dos professores às perguntas norteadoras do estudo.

\section{RESPOSTAS DOS PROFESSORES}

P1 Desafios enfrentados durante a transição do ensino presencial - remoto.

P2 Desafios da docência remota.

P3 Relação entre o EAD e as Gap tecnológico de uma geração de professores.

$P 4$

Dificuldades na transição do ensino presencial para o ensino EAD em meio às novas adequações exigidas institucionalmente.

P5 Aulas remotas em tempos de pandemia.

P1 Desafios e vantagens de adotar uma nova modalidade de ensino no contexto amapaense.

$P 2 \quad$ Desafios de transformar subitamente um ensino tradicionalmente presencial em remoto.

P3 Desafios na utilização das ferramentas digitais e a desvalorização do ensino remoto.

$P 4$

Dificuldades na transição do ensino presencial para o ensino EAD e a estratégia individual para melhor se adequar às demandas presentes.

P5 Como foi desafiador lidar e ensinar com as novas tecnologias.

P1 A grande capacidade do ser humano de se superar diante de situações desafiadoras.

P2 Aprendizagem de novas técnicas de docência aliadas à gestão, aulas e atividades.

P3 Disponibilidade das ferramentas para o ensino.

P4 Abertura para a experiência, importância da resiliência e da organização de tempo.

P5

P1

P2

P3

P4

Novos meios de explorar o ensino; utilização de novas ferramentas e maneiras de prender a atenção dos alunos.

O acesso à internet, conseguir despertar o interesse dos acadêmicos, desafio de equilibrar a rotina pessoal e profissional no isolamento.

Internet deficiente do estado.

3 Gestão de informação e tempo da aula remota.

4 Estratégia de organização e manejo do tempo.

5 Dificuldade de planejamento; dificuldade de internet e problemas de adaptação por parte dos alunos.

$P^{*}$ : Novas experiências como o uso de ferramentas digitais.

$N^{*}$ : Relações acadêmicas aluno-professor empobrecidas e aumento nas horas dedicadas ao trabalho. 
P2 $\quad P^{*}$ : Praticar a capacidade de se reinventar e se adaptar ao novo.

$N^{*}$ : Perder o contato físico com os alunos e professores.

$P 3 \quad P^{*}$ : Flexibilidade e versatilidade do professor.

$N^{*}:$ Forma engessada que algumas instituições de ensino adotaram como modelo remoto

$P 4 P^{*}$ : Estratégias de estudo desenvolvidas na ilustração científica, e na oratória.

$N^{*}$ : Falta de retorno durante as aulas.

P5 $\quad P^{*}:$ Flexibilidade em ministrar as aulas de qualquer lugar.

$N^{*}$ : Desinteresse dos alunos pelo ensino remoto.

P1 Desenvolver formas alternativas para ministrar aulas práticas no modelo remoto assim como métodos que permitam ao professor manter contato visual com os acadêmicos durante a realização das provas.

P2 Está sendo feito tudo o que está ao nosso alcance, a retomada de algumas atividades paradas como os congressos e ligas acadêmicas.

P3 A qualificação continuada do professor e o estímulo do aluno por diversos canais são fundamentais neste momento.

P4 Necessidade de avaliações e reflexões sobre a educação na pandemia com aspectos objetivos e subjetivos que dificultem a interação entre alunos e professores.

P5 Discussão de novas ideias, processos, ferramentas e técnicas para o melhor aprendizado.

Nota: P: Professor; V: Acadêmico veterano, C: calouro. $\mathrm{P}^{*}$ : aspectos positivos, $\mathrm{N}^{*}$ : aspectos negativos.

Fonte da tabela: Autoria própria.

Ao verificar as respostas do segundo grupo, de acadêmicos veteranos, (resumidas na Tabela 4) conclui-se a singularidade das vertentes abordadas por cada integrante, sem que ocorra o desvio do tema proposto.

Entre as questões levantadas estão: os desafios enfrentados pelos professores e acadêmicos em relação ao uso das ferramentas digitais, as plataformas que são utilizadas para a feitura de atividades e provas, e as dificuldades enfrentadas para que se tenha uma educação de qualidade visto os problemas com a internet no estado. Outro aspecto abordado por um dos veteranos está relacionado à flexibilidade que o ensino remoto proporciona, referente à opção que o aluno possui de assistir as aulas gravadas no momento que lhe for oportuno ou acessível, principalmente para os estudantes trabalhadores.

Em primeiro plano o grupo ressalta a precariedade da internet no estado do Amapá, especificamente no município de Macapá. Neste sentido, uma notícia publicada pelo G1 (2015) revela dados sobre a internet lenta:

Um mapeamento feito pelo G1 com dados da Agência Nacional de Telecomunicações (Anatel), divulgado na quartafeira (13), apontou que Macapá é a capital brasileira que oferece a menor média de velocidade de internet banda larga do país, onde a maioria dos 16.418 pontos de acesso operam entre 512 Kbps e 2 Mbps, uma taxa considerada baixa em relação à média do país, que gira em torno de $3 \mathrm{Mbps}$.

Outro assunto citado por um dos veteranos foi o trágico acontecimento na noite de 3 de novembro, um incêndio na subestação de Macapá que provocou o início de um apagão que duraria mais de 20 dias. A falta de energia impactou, dentre outros fatores os serviços de internet e de telefonia. Vale ressaltar que antes mesmo do blecaute, tais problemas não são novidades para os macapaenses, que há muito tempo vem enfrentando momentos relacionados à queda de energia e deficiência nos serviços de comunicação. Além disso, esse ocorrido gerou um forte abalo emocional. Na esfera educacional especificamente, ficou evidente, tanto para os discentes e docentes, que ficaram impossibilitados de prosseguir as atividades acadêmicas. 
Para os veteranos, importantes aprendizados foram destacados e levados em consideração. A mudança de maior destaque apontada foi o uso de diferentes plataformas digitais disponíveis para facilitar a gestão das aulas remotas. No primeiro momento, o manuseio das ferramentas foi um empecilho enfrentado principalmente para os não adeptos a essas tecnologias, porém com o estudo e aquisição de tutoriais, toda essa aparelhagem se revelou como principal aliada para adquirir conhecimento.

Não se limitando a apenas as ferramentas tecnológicas, outro fator decisivo para estudar e obter resultados da mesma forma tradicional de ensino, sobrevém de acompanhar as aulas virtuais, se adequar a essa nova modalidade. O ambiente de sala de aula, agora se realoca no espaço onde vivem os acadêmicos e professores e, portanto se firmar a um método de estudo, para acompanhar a explicação do docente é de suma importância para o entendimento do assunto.

Tabela 4. Respostas dos acadêmicos veteranos às perguntas norteadoras do estudo.

\begin{tabular}{|c|c|c|}
\hline PERGUNTAS & & RESPOSTAS DOS VETERANOS \\
\hline \multirow{3}{*}{$\# 1$} & $V 1$ & Utilização de plataforma para prova. \\
\hline & $\boldsymbol{V} 2$ & $\begin{array}{l}\text { Desafios dos professores e acadêmicos com as plataformas digitais no novo "normal". } \\
\text { Apagão ocorrido no estado do Amapá no dia } 03 \text { de nov. de } 2020 .\end{array}$ \\
\hline & V3 & Flexibilidade do estudo remoto. \\
\hline \multirow{3}{*}{$\# 2$} & V1 & Precariedade na internet do estado, algo que afronta o ensino remoto. \\
\hline & V2 & Desafio com as plataformas digitais e a crise de energia em decorrência do apagão. \\
\hline & V3 & Como ele me ajudou a conciliar o estudo com os trabalhos do dia a dia. \\
\hline \multirow{3}{*}{ \#3 } & $V 1$ & $\begin{array}{l}\text { Que mesmo sendo algo virtual, precisamos anotar e manter o método presencial de } \\
\text { escrever. }\end{array}$ \\
\hline & $\mathbf{V 2}$ & $\begin{array}{l}\text { Aprendemos a importância da contribuição no contexto pandêmico. Ajudando o próximo } \\
\text { de todas as formas possíveis. }\end{array}$ \\
\hline & V3 & $\begin{array}{l}\text { A pandemia trouxe à tona métodos e ferramentas tecnológicas para que continuássemos os } \\
\text { estudos e que tivéssemos satisfação no ambiente virtual. }\end{array}$ \\
\hline \multirow{3}{*}{ \#4 } & V1 & Provedores de internet local. \\
\hline & V2 & $\begin{array}{l}\text { Problemas na internet. Houve ocorrências de perda da conexão, comprometendo a feitura } \\
\text { e finalização da prova. }\end{array}$ \\
\hline & V3 & Precariedade da internet e as constantes faltas de energia em nossa região. \\
\hline \multirow{3}{*}{$\# 5$} & $V 1$ & $\begin{array}{l}P^{*}: \text { Gerou aprendizado. } \\
N^{*}: \text { Consumiu mais tempo. }\end{array}$ \\
\hline & $\boldsymbol{V} 2$ & $\begin{array}{l}P^{*}: \text { Trabalhos dinâmicos, compromisso e preocupação por parte dos professores. } \\
N^{*}: \text { Internet do estado, além das ferramentas digitais que eu não tinha. }\end{array}$ \\
\hline & V3 & $\begin{array}{l}P^{*}: \text { Flexibilidade em poder conciliar o estudo com algumas tarefas do dia a dia, sem } \\
\text { perder o foco principal que é o aprendizado. }\end{array}$ \\
\hline \multirow{3}{*}{ \#6 } & $V 1$ & Sempre deixar ciente à coordenação sobre os ocorridos com a internet. \\
\hline & $V 2$ & $\begin{array}{l}\text { Poderiam ser feitos alguns projetos de reforço, de produções de artigos. } \\
\text { Os projetos aumentariam a vontade de estar na aula e de participar. }\end{array}$ \\
\hline & $V 3$ & $\begin{array}{l}\text { Estou muito satisfeito com a dinâmica das aulas e como os professores conduzem a } \\
\text { disciplina. }\end{array}$ \\
\hline
\end{tabular}

Nota: P: Professor; V: Acadêmico veterano, C: calouro. $\mathrm{P}^{*}$ : aspectos positivos, $\mathrm{N}^{*}$ : aspectos negativos.

Fonte da tabela: Autoria própria.

Em decorrência desses fatores, a contribuição e compressão de todos, tornam-se indispensáveis para o avanço do processo de ensino. De acordo com esse grupo, nas circunstâncias atuais de incerteza, a coletividade é a base do sistema de 
ensino remoto, portanto é importante o entendimento e o desenvolvimento dessa relação. Em vista disso, para os veteranos, essa experiência tem sido tanto um aprendizado como um ponto positivo.

Enquanto a fatores que precisam ser melhorados, ou reelaborados, esse grupo apresentou uma visão positiva referente às decisões e atitudes que estão sendo adotados pela instituição IMMES. Mas vale destacar a recomendação de um dos acadêmicos sobre os benefícios que atividades extracurriculares poderiam vim a proporcionar, como projetos de reforço de algumas disciplinas assim como a produção de artigos científicos, visando despertar ainda mais o interesse e a efetividade de aprender o conteúdo.

Tabela 5. Respostas dos calouros às perguntas norteadoras do estudo.

\section{PERGUNTAS}

\section{RESPOSTAS DOS CALOUROS}

\begin{tabular}{|c|c|c|}
\hline \multirow{3}{*}{ \#1 } & $C 1$ & Uso de tecnologias educacionais em tempos de pandemia. \\
\hline & $C 2$ & Tecnologias educacionais. \\
\hline & C3 & Mudança das aulas presencias para as aulas online. \\
\hline \multirow{3}{*}{ \#2 } & C1 & $\begin{array}{l}\text { Necessidade dos docentes, discentes e as instituições educacionais como um todo se } \\
\text { reinventarem em meio à crise mundial causada pela COVID } 19 .\end{array}$ \\
\hline & $C 2$ & $\begin{array}{l}\text { Sobre a tecnologia educacional. É um conceito que diz respeito à utilização de recursos } \\
\text { tecnológicos para fins pedagógicos. }\end{array}$ \\
\hline & C3 & Experiência com a aula online no ensino médio. \\
\hline \multirow{3}{*}{ \#3 } & $C 1$ & $\begin{array}{l}\text { A compreensão e colaboração de todos. A instituição deve manter a transparência no contato } \\
\text { com o estudante. }\end{array}$ \\
\hline & $C 2$ & $\begin{array}{l}\text { Toda evolução compreende uma mudança na comunicação, nas relações sociais e no processo } \\
\text { de ensino e aprendizagem. }\end{array}$ \\
\hline & C3 & $\begin{array}{l}\text { Eu e minha turma tivemos que nos adaptar ao novo formato de ensino e aprender a mexer nas } \\
\text { plataformas em que eram feitas as aulas e atividades. }\end{array}$ \\
\hline \multirow{3}{*}{ \#4 } & $C 1$ & $\begin{array}{l}\text { As disciplinas estavam sendo passadas em grande quantidade e com um curto espaço de tempo } \\
\text { para absorção e aprendizagem. }\end{array}$ \\
\hline & $C 2$ & No início, houve dificuldades, por não ter as ferramentas digitais necessárias. \\
\hline & C3 & $\begin{array}{l}\text { As dificuldades do uso das ferramentas digitais e o aumento de distrações que desviam nossa } \\
\text { atenção da aula, como: celular e familiares. }\end{array}$ \\
\hline \multirow{3}{*}{$\# 5$} & $C 1$ & $\begin{array}{l}P^{*} \text { : Disponibilidade de matérias digitais e conexão com a rede. } \\
\text { II. Facilidade de perder o foco na aula e a falta de convivência com as pessoas. }\end{array}$ \\
\hline & $C 2$ & $\begin{array}{l}P^{*}: \text { Facilidade de perder a concentração II. A opção de estudar em um local confortável e } \\
\text { reservado. }\end{array}$ \\
\hline & C3 & Não houve resposta do respondente \\
\hline \multirow{3}{*}{ \#6 } & C1 & Planejamento de recursos extras efetivos para o ambiente virtual não se tornar monótono. \\
\hline & $C 2$ & $\begin{array}{l}\text { Têm sido satisfatório o rumo que o IMMES vem trabalhando, todas as medidas necessárias } \\
\text { estão sendo realizadas. }\end{array}$ \\
\hline & C3 & O empenho dos alunos nas aulas e atividades. \\
\hline
\end{tabular}

Nota: P: Professor; V: Acadêmico veterano, C: calouro. $\mathrm{P}^{*}$ : aspectos positivos, $\mathrm{N}^{*}$ : aspectos negativos.

Fonte da tabela: Autoria própria.

Ao verificar as respostas do terceiro grupo, de calouros, (resumidas na Tabela 5), se observaram respostas compatíveis entre si e come os grupos anteriores (professores e veteranos), trazendo discussões acerca do uso das ferramentas educacionais e as experiências de vivenciar a mudança das aulas presenciais para as aulas remotas. 
Essa equipe explanou que o ser humano, frente aos obstáculos, busca se adaptar, transformar, aderir, reformular e avaliar os seus métodos de pesquisa, ação e conduta, visando viver com qualidade. Tendo em vista o fechamento das instituições educacionais, incluindo o IMMES, foi preciso considerar duas etapas distintas: adequação, que implica assimilar o ambiente e ajustar os problemas mais simples, para dar continuidade aos trabalhos, e a transformação, que requer a mudança de um estado para o outro, com alterações duradouras.

Ainda concluíram que o modelo de ensino remoto representou não só uma mudança na comunicação e nas relações sociais, mas também nos métodos de ensino e aprendizado. E no decorrer dessa adequação, foram apresentadas plataformas e ferramentas já existentes, mas pouco conhecidas por esse grupo. $\mathrm{O}$ uso dessas tecnologias tem sido um processo desafiador, ademais, têm gerado importantes lições, tanto de conteúdo disciplinar, como significativas interações sociais.

A EAD deixa de oferecer um ensino de caráter paliativo ou emergencial e passa a responsabilizar-se por algo de cunho e credibilidade crescente. Contudo, faz-se necessário, saudar com otimismo a obsolência acelerada, da tecnologia na construção do conhecimento, uma vez que esta tem objetivado a integração de esforços para a consolidação de educação à distância, sobretudo na formação de professores, em todos os níveis. (Jesus, 2017)

As ferramentas digitais, como dito anteriormente, além de auxiliar, é o principal meio no qual está sendo realizado todo o processo de ensino e interação. Contudo, é preciso admitir, que no início do processo, houve muitas dificuldades em relação ao uso, e aos métodos de ensino aplicados em algumas escolas e faculdades.

Os desafios citados pelos calouros incluíam a grande quantidade de assuntos passados pelos professores, não permitindo tempo suficiente para absorção e aprendizagem; as dificuldades de manter o hábito de escrever, visto que as aulas eram apenas de forma oratória ou apresentação de slide, não permitindo tempo suficiente para copiar as informações.

Outro problema enfrentado por um dos calouros foi a carência do aparato tecnológico logo no início das aulas remotas e as dificuldades de usar as plataformas digitais, somando ainda aos contratempos causados por acontecimentos fora da aula online, e a facilidade de se distrair durante as aulas, perdendo completamente o foco e o compromisso.

Porém o contexto de isolamento tem exigido das pessoas e de suas famílias adaptarem-se a situações diversas e, muitas vezes, adversas, tais como o desemprego elou a redução dos vencimentos, o cuidado com os mais idosos e as crianças, a reunião de várias pessoas em casas com poucos cômodos, além de baixa qualidade ou falta de acesso à internet. (UFRGS, 2020)

O isolamento social foi uma das medidas adotadas para conter o avanço da Covid-19. É perceptível os seus impactos na educação, assim como em todas as esferas sociais. A socialização acadêmica tem um grande papel desde sempre na formação individual. O ambiente universitário é um cenário vivo de interações, de trocas explícitas de ideias, valores e diferentes.

No Brasil, o caráter social da escola é sustentada por lei- mais precisamente a Lei $\mathrm{n}^{\circ}$ 9394, de 20 de dezembro de 1996, que estabelece as diretrizes da educação nacional:

"Art.1o A educação abrange os processos formativos que se desenvolvem na vida familiar, na convivência humana, no trabalho, nas instituições de ensino e pesquisa, nos movimentos sociais e organizações da sociedade civil e nas manifestações culturais.

Com a prática e familiarização, fica claro os benefícios e a versatilidade que as ferramentas podem proporcionar. Dentre os pontos positivos citados pela equipe estão: a flexibilidade de se estudar em qualquer lugar, de preferência em casa, ou um local reservado e adequado para se concentrar; o acesso à internet, quando usada de maneira correta se torna uma grande aliada, promovendo conhecimento de maneira instantânea, visto que é de rápido e fácil acesso. Até porque ela é 
necessária para a gestão dos conteúdos, as atividades, apresentações, comunicação e o acesso às aulas online.

Depois de analisadas as respostas, fica evidente que a privatização desse contato no ambiente educacional, gera uma carga emocional muito grande, visto a importância do outro não só no processo de construção do conhecimento, mas também na composição do próprio sujeito e de suas formas de agir. Além disso, a figura do educador nesse espaço de interações ocupa um papel fundamental, ele se coloca como mediador e facilitador desses processos de significações. Nesse âmbito, a participação integral dos alunos por meio das ferramentas digitais determinará a efetividade das relações de alunos, professores e todos os associados.

Diante desses pontos levantados pelos calouros, foi contestado de maneira geral a aprovação e satisfação pela faculdade IMMES, e todas as medidas de precaução por ela adotadas. Dentro do que foi concluído, vale considerar ainda, a consideração feita pelo discente, afirmando sobre a importância do planejamento de recursos extras efetivos para que o ambiente virtual não se torne cansativo ou mecânico em prol do aperfeiçoamento pedagógico.

Não obstante é notabilizado pelas declarações, que a atuação deste instituto, tem sido condecorado, dentre outros fatores pelo desempenho simbólico, acessível, e transparente com todos os discentes, aspirando sempre desenvolver, e prestar o melhor método de gestão educacional.

Dentre os aspectos positivos do ensino remoto foram observados a flexibilidade para organizar o tempo de realizar e entregar atividades, economia de tempo e dinheiro, pois em certos momentos dispensa tempo e principalmente custos com deslocamentos. Também foi revelado que este modelo propicia um espaço de interação aberto à inovação pedagógica e proporciona uma oportunidade para pessoas tímidas aprenderem de forma confortável e entrar em contato via whatsapp para esclarecer dúvidas.

O presente relato de experiência, tratou-se de um estudo descritivo, de caráter qualitativo, no qual foi fundamental a opinião dos entrevistados sobre o assunto analisado. Posteriormente, o estudo qualitativo poderá se transformar em quantitativo por meio do emprego de questões fechadas, por exemplo, pelo emprego da Escala Likert. Nessa escala, em cada questão, deverão ser feitas afirmações e os entrevistados escolherão um número de 1 a 5 relacionado com graus de concordância em relação à afirmação. (Estrela, 2018; Pereira et al., 2018; Ludke \& Andre, 2013).

\section{Considerações Finais}

O presente estudo permitiu, primeiramente, expor os principais desafios encontrados por acadêmicos e professores amapaenses para continuar com as atividades acadêmicas durante a pandemia do Covid 19, sendo apontada como principal dificuldade a precariedade no sistema de Internet no estado. Por outro lado, o estudo também revelou aspectos positivos do ensino online, demonstrando que o Google Meet e Classroom são ferramentas profícuas para o ensino superior face aos fatores que ainda impossibilitam a volta às aulas presenciais. Contudo, é importante destacar que a tecnologia não substitui a interação presencial aluno-professor. Os resultados esperados foram atingidos com sucesso, no que se refere à análise e conclusões formadas a partir da perspectiva reportada pelos entrevistados no que concerne ao uso das tecnologias educacionais em tempos de pandemia no ambiente escolar virtual, possibilitando assim a expansão dos horizontes de informações sobre os desafios e o uso conveniente que as ferramentas de ensino remoto proporcionaram. Assim, os dados levantados através desta pesquisa servirão como ponto de partida para o desenvolvimento de estratégias pedagógicas remotas que permitam melhorar o processo de ensino- aprendizagem até o retorno as aulas presenciais, garantindo o compromisso institucional de oferecer uma formação profissional de alta qualidade. Contudo, é recomendado realizar posteriormente um estudo quantitativo, por meio de questionário com questões fechadas a serem aplicados a um número maior de indivíduos, que permita avaliar de forma mais eficaz os impactos do emprego destas tecnologias digitais no IMMES, o que permitirá as autoridades competentes verificar a viabilidade do método de ensino hibrido online/remoto, no fim da pandemia. 


\section{Agradecimentos}

Os autores agradecem à coordenação do Curso de Farmácia e à direção geral do Instituto Macapaense de Melhor Ensino Superior (IMMES) pelo apoio à pesquisa.

\section{Referências}

Alencar, D. C., Passos, J. A., Carvalho, A. C. B., Ibiapina, A. R. S., Carvalho, D. B. F., \& Vasconcellos-Silva, P. R. (2020). Busca de informações sobre o novo coronavírus no Brasil: uma análise da tendência considerando as buscas online. Acta Paul Enferm, 33:1-8.

Awwalu, M. I. (2020) Re-theorizing nigerian school functions for predicting institutional accountability on students. Kashere Journal of Education, 1(2):1839 .

Barreto, J. DA S., Amorim, M. R. O. R. M., \& Cunha, C. da. (2020). A pandemia da Covid-19 e os Impactos na Educação. Revista JRG de Estudos Acadêmicos, 3(7):792-805.

Buheji, M., Cunha, K. C., Beka, G., Mavric, B., Souza, Y. L. C., Silva, S. S. C., Hanafi, M., \& Yein, T. C. (2020) The Extent of COVID-19 Pandemic SocioEconomic Impact on Global Poverty. A Global Integrative Multidisciplinary Review. American Journal of Economics, 10(4):213-224.

Cucinotta, D., \& Vanelli, M. (2020). WHO declares COVID-19 a pandemic. Acta Biomedica, 91(1):157-160.

Dharmaratne, S., Sudaraka, S., Abeyagunawardena. I., Manchanayake, K., Kothalawala, M., \& Gunathunga, W. (2020). Estimation of the basic reproduction number (R0) for the novel coronavirus disease in Sri Lanka. Virology Journal, 17(1):1-7.

Estrela, C. (2018). Metodologia Científica: Ciência, Ensino, Pesquisa. Editora Artes Médicas.

Fernandes, N. (2020). Economic effects of coronavirus outbreak ( COVID-19) on the world economy Nuno Fernandes Full Professor of Finance IESE Business School Spain. SSRN Electronic Journal, 0-29.

Gravinatti, M. L., Barbosa, C. M., Soares, R. M., \& Gregori, F. (2020). Synanthropic rodents as virus reservoirs and transmitters. Revista da Sociedade Brasileira de Medicina Tropical, 53(11):1-11.

Lan, A. S., Brinton, C. G., Yang, T. Y., \& Chiang, M. (2017). Behavior-based latent variable model for learner engagement. Proceedings of the 10th International Conference on Educational Data Mining, 64-71.

Liu, Y., Gayle, A. A., Wilder-Smith, A., \& Rocklöv, J. (2020) The reproductive number of COVID-19 is higher compared to SARS coronavirus. Journal of Travel Medicine, 27(2):1-4.

Ludke, M., \& Andre, M. E. D. A. (2013). Pesquisas em educação: uma abordagem qualitativa. São Paulo: E.P.U.

Maital, S., \& Barzani, E. (2020). The global economic impact of COVID-19: A summary of research. Samuel Neaman Institute for National Policy Research, $3: 1-12$.

Matão, M. E. L., Miranda, D. B., Campos, P. H. F., Oliveira, L. N., \& Martins, V. R. (2011). Experiência de familiares na vivência da depressão pós-parto. Revista de Enfermagem do Centro-Oeste Mineiro, 1(3): 283-293.

Parhanudin, A., \& Mataram, U. I. N. (2020). Analysis of social structure and power. Jurnal Sophist, 2(1):1-37.

Pereira A. S., et al. (2018). Metodologia da pesquisa científica. [free e-book]. Santa Maria/RS. Ed. UAB/NTE/UFSM.

Ranieri, L. P., \& Barreira, C. R. A. (2021). A empatia como vivência. Memorandum: Memória e História em Psicologia, 23:12-31.

Rose, T., Lindsey, M. A., Xiao, Y., Finigan-Carr, N. M., \& Joe, S. (2017). Mental Health and Educational Experiences Among Black Youth: A Latent Class Analysis. Journal of Youth and Adolescence, 46(11):2321-2340.

Viesenteiner, J. L. (2013). O conceito de vivência (Erlebnis) em Nietzsche: Gênese, significado e recepção. Kriterion (Brazil), 54(127):141-155.

Wu, Z., \& McGoogan, J. M. (2020). Characteristics of and Important Lessons from the Coronavirus Disease 2019 (COVID-19) Outbreak in China: Summary of a Report of 72314 Cases from the Chinese Center for Disease Control and Prevention. Journal of the American Medical Association, 323(13):1239-1242.

Zhang, S., Diao, M. Y., Yu, W., Pei, L., Lin, Z., \& Chen, D. (2020). Estimation of the reproductive number of novel coronavirus (COVID-19) and the probable outbreak size on the Diamond Princess cruise ship: A data-driven analysis. International Journal of Infectious Diseases, 93:201-204. 